\title{
Treatment Outcomes for Patients Undergoing Hemodialysis with Chronic Hepatitis C on the Sofosbuvir and Daclatasvir Regimen
}

\author{
Nazish Butt ${ }^{1}$, Amanullah Abbasi ${ }^{2}$, M Ali Khan ${ }^{1}$, Muhammad Ali ${ }^{3}$, Ghulam B. Mahesar ${ }^{4}$, Farhan Haleem \\ 1 , Abdul Manan ${ }^{3}$ \\ 1. Gastroenterology, Jinnah Postgraduate Medical Centre, Karachi, PAK 2. Internal Medicine, Dow University of Health \\ Sciences, Karachi, PAK 3. Nephrology, Jinnah Postgraduate Medical Centre, Karachi, PAK 4. Internal Medicine, Jinnah \\ Postgraduate Medical Centre, Karachi, PAK
}

Corresponding author: M Ali Khan, aleekhan3333@gmail.com

\section{Abstract \\ Background}

Hepatitis C (HCV) infection is the most commonly acquired infection for patients on hemodialysis and is associated with significant morbidity and disease progression. Direct-acting antivirals (DAAs) have revolutionized the management of HCV. However, limited data exist regarding their efficacy in end-stage renal disease (ESRD), especially for patients on dialysis in South Asia.

\section{Aims}

To evaluate the treatment outcomes of patients undergoing hemodialysis with chronic hepatitis $\mathrm{C}$ (CHC) on the sofosbuvir (SOF) and daclatasvir (DAC) regimen.

\section{Materials and methods}

All patients who were 18 years or older, diagnosed cases of chronic kidney disease (stage V), and undergoing maintenance hemodialysis were inducted into this study. Active HCV infection was demonstrated by polymerase chain reaction (PCR) HCV ribonucleic acid (RNA) (qualitative). All patients were then treated with a double regimen of SOF ( $400 \mathrm{mg}$ once daily) and DAC ( $60 \mathrm{mg}$ once daily) taken per oral for 12 weeks. Response to treatment was assessed at four, 12, and 52 weeks.

\section{Results}

A total of 31 out of 80 patients were inducted into the study over two years. The prevalence of HCV in hemodialysis patients was $38.75 \%$. Sustained virological response (SVR) was achieved by 27 ( $87.09 \%)$ patients at one year. Four (12.90\%) patients had a relapse of HCV. There was no deterioration of hepatological status in any of the patients. Overall survival at one year was $93.54 \%$.

Received 09/08/2019

Review began 09/15/2019 Review ended 09/18/2019 Published 09/19/2019

(c) Copyright 2019

Butt et al. This is an open access article distributed under the terms of the Creative Commons Attribution License CC-BY 3.0., which permits unrestricted use, distribution, and reproduction in any medium, provided the original author and source are credited.

\section{Conclusion}

HCV is highly prevalent in patients undergoing hemodialysis. Prompt treatment with SOF and DAC demonstrates a good response, with negligible side effects.

Categories: Gastroenterology, Infectious Disease, Nephrology

Keywords: end-stage-renal-disease, hep c, sofosbuvir, daclatasvir, hemodialysis

\section{Introduction}

Chronic kidney disease (CKD) in South Asia is highly prevalent, notably in developing countries. The prevalence of CKD in Pakistan is estimated to be around 23\% [1]; most of these estimates are from studies conducted within the urban areas, especially urban Karachi. A large number of these patients eventually require hemodialysis for the maintenance of normal renal function.

While numbers vary from $60 \%-82 \%$ of patients with CKD requiring dialysis, increasing age and comorbidities are associated with a higher and earlier need for dialysis [2]. Once CKD patients are put on hemodialysis, they are at an increased risk of complications such as myocardial infarction, iron deficiency anemia, acquired infections, fistula formation, and osteoporosis, to name a few [3-4].

Acquired infections are common and associated with increased morbidity and mortality. Chronic hepatitis $\mathrm{C}$ (CHC) is the most commonly transmitted infection in CKD patients on hemodialysis; it is also one of the causes of CKD itself [5]. The natural course of CHC with CKD isn't simple and both diseases affect each 
other. CHC is associated with a greater risk of cardiovascular and liver-related mortality in patients on dialysis [6].

Historically, treatment for $\mathrm{CHC}$ was arduous even for patients without CKD, even more so for patients on maintenance hemodialysis. With polyethylene glycol (PEG)-interferon, only $39 \%$ of patients exhibited viral eradication. Overall, a sustained virological response was not achieved even if it was tolerated [7]. Directacting antivirals (DAAs) are a newly developed class of drugs that have shown great efficacy in treating CHC.

For patients on hemodialysis taking DAAs, viral elimination rates of as high as $99 \%$ have been seen, with little or no adverse events [8], mostly for genotypes 1,4 , and 6 . However, little data is available on the treatment outcomes with sofosbuvir and daclatasvir. Even less data is available on genotype 3 in this aspect. Couple the above facts with respect to Pakistan and almost no data is available at all, something we look to rectify here.

\section{Materials And Methods}

Data were collected from Ward 23, Gastroenterology, and Ward 22, Nephrology, Jinnah Postgraduate Medical Centre, Karachi. This study was held from January 2017 to December 2018. Approval from the ethical committee/board of the institute had been taken. All information was kept confidential. Written consent was taken from all patients.

Initial screening for HCV was done via the enzyme-linked immunosorbent assay (ELISA) test for the HCV antibody. Only patients that had a positive result were further tested. Patients were made fully aware of the procedures that were being carried out and the regimen used to treat chronic hepatitis $\mathrm{C}(\mathrm{CHC})$ was provided free of cost.

\section{Inclusions criteria}

Patients of either gender, who were 18 years or older and met the following criteria, were inducted into the study:

1. A positive qualitative polymerase chain reaction (PCR) result and genotype detection indicative of an active HCV infection.

2. Already diagnosed cases of HCV, with proven active replication.

3. Patients who were undergoing maintenance hemodialysis due to end-stage renal disease (ESRD), defined as a glomerular filtration rate (GFR) of less than $30 \mathrm{~mL} / \mathrm{min} / 1.73 \mathrm{~m}^{2}$, which required weekly hemodialysis sessions to maintain renal functions.

\section{Exclusion criteria}

1. Patients with decompensated liver disease or compensated cirrhotics (on the basis of clinical, history, and lab findings)

2. Patients with terminal or metastatic malignancy

3. HIV co-infected patients

4. HBV co-infected patients

5. Intravenous (I/V) drug abusers

6. Other co-infections, such as Mycobacterium tuberculosis, fungal infections, or other opportunistic infections

7. Alcoholics

\section{Primary outcome}

The primary outcome was to achieve viral elimination from the serum. PCR was done at selected intervals to evaluate the response to treatment. Rapid virological response (RVR) was seen at four weeks since starting treatment, end of treatment response (ETR) was seen at 12 weeks, and sustained virological response (SVR) was evaluated at 52 weeks since starting treatment.

\section{Secondary outcome}

The eventual course of ESRD and liver status at one year was also assessed. Any deterioration in the liver 


\section{Cureus}

function and disease progression for both CKD and CHC were recorded.

\section{Drug regimen}

Sofosbuvir (SOF) is an inhibitor of the NS5B nonstructural protein and daclatasvir (DAC) is an inhibitor of NS5A nonstructural protein. These phosphoproteins play an important role in hepatitis $\mathrm{C}$ replication. For patients without cirrhosis, DAC was used in combination with SOF according to the guidelines of that time. We used the following regimen:

- DAC 60 mg once daily per oral + SOF 400 mg once daily per oral for 12 weeks

Note: The medicine was given OFF-LABEL to all patients free of cost. At the time of this study, other newer DAAs, such as Ombitasvir, Grazoprevir, Paritaprevir with Ritonivir, etc., were neither licensed nor available for use in Pakistan (even for clinical trials).

\section{Laboratorical analysis}

All baseline labs were done at period intervals of four, 12, and 52 weeks after induction into the study. These included complete blood count (CBC), prothrombin time (PT), international normalized ratio (INR), urea and creatinine levels, with serum electrolytes. Ultrasound of the abdomen was also carried out. All this was free of cost for the patients.

\section{Data analysis and sampling technique}

The nonprobability convenient sampling technique was used. Statistical Package for the Social Sciences (SPSS) version 21.0 software (SPSS Inc., Chicago, IL, USA) was employed.

\section{Results}

Of the 80 patients that were screened over two years, 25 patients had a positive result for HCV antibody. Six patients were previously diagnosed cases of HCV with active infection were also included. Incidentally, all 31 also had positive PCR as well, putting the prevalence at $38.75 \%$.

\section{Demographic and baseline characteristics}

Patients were predominantly female, middle-aged, and housewives. Demographic details are shown in Table 1. Patients had low mean hemoglobin $(\mathrm{Hb})$ as one would expect in $\mathrm{CKD}$, no other abnormality could be seen. Baseline characteristics are summarized in Table 2.

\begin{tabular}{|c|c|}
\hline & $(\mathrm{N}=31)$ \\
\hline Age (mean) & $36.52 \pm 10.90$ years \\
\hline \multicolumn{2}{|l|}{ Gender } \\
\hline Male & $11(35.48 \%)$ \\
\hline Female & $20(64.51 \%)$ \\
\hline \multicolumn{2}{|l|}{ Marital Status } \\
\hline Married & $26(83.87 \%)$ \\
\hline Not Married & $5(16.12 \%)$ \\
\hline \multicolumn{2}{|l|}{ Occupation } \\
\hline Housewife & $20(64.51 \%)$ \\
\hline Laborer & 04 (12.90\%) \\
\hline Shopkeeper & 03 (9.67\%) \\
\hline Other & 04 (12.90\%) \\
\hline
\end{tabular}

TABLE 1: Demographics 


\section{Cureus}

\begin{tabular}{|l|l|}
\hline Age (mean) & $(\mathbf{N}=31)$ \\
\hline Gender & $36.52 \pm 10.90$ years \\
Male & $11(35.48 \%)$ \\
\hline Female & $20(64.51 \%)$ \\
Marital Status & \\
Married & $26(83.87 \%)$ \\
Not Married & $5(16.12 \%)$ \\
Occupation & \\
Housewife & $20(64.51 \%)$ \\
Laborer & $04(12.90 \%)$ \\
Shopkeeper & $03(9.67 \%)$ \\
Other & $04(12.90 \%)$ \\
\hline
\end{tabular}

TABLE 2: Baseline characteristics

\section{Renal, electrolyte, and dialysis profile}

Creatinine and urea understandably were on the higher side with patients requiring a median of three dialysis sessions per week. Hypertension was the most common cause of CKD requiring dialysis. The renal and electrolyte profile is given in Table 3 and the dialysis profile in Table 4.

\begin{tabular}{|l|l|}
\hline & $(\mathrm{N}=31)$ Mean \\
\hline Creatinine & $7.82 \pm 2.75$ \\
Urea & $117.87 \pm 36.37$ \\
Sodium & $136.00 \pm 4.11$ \\
Potassium & $4.37 \pm 0.82$ \\
Bicarbonate & $23.53 \pm 2.41$ \\
Phosphate & $6.96 \pm 1.42$ \\
Calcium & $7.78 \pm 0.77$ \\
\hline
\end{tabular}

TABLE 3: Renal and electrolyte profile 


\section{Cureus}

\begin{tabular}{|l|l|}
\hline Cause of Chronic Kidney Disease/Dialysis & (N=31) \\
\hline Hypertension & $12(38.7 \%)$ \\
\hline Miscellaneous* & $07(22.6 \%)$ \\
\hline Bilateral Small Size Kidney Disease (BSSKD) & $06(19.4 \%)$ \\
\hline Diabetes & $04(12.9 \%)$ \\
\hline Renal Stone Disease & $02(6.5 \%)$ \\
\hline Duration of dialysis per week (median) & $03 /$ week \\
\hline Duration of ongoing dialysis (mean) & $3.37 \pm 1.54$ years \\
\hline `These include chronic tubulointerstitial nephritis, multiple myeloma, pregnancy-induced renal disease, amyloidosis, and echogenic kidneys.
\end{tabular}

TABLE 4: Dialysis profile

\section{Liver and serological profile}

A majority of the patients were genotype 3 (GT-3) and treatment naïve. The liver function test was representative of chronic liver disease without decompensation or cirrhosis. Any alterations seen could only be attributed to CKD rather than CHC. Liver and viral profiles are summarized in Tables 5-6.

\begin{tabular}{|l|l|}
\hline Alanine Aminotransferase (ALT) & (N=31) \\
\hline Aspartate Aminotransferase (AST) & $37.25 \pm 47.10$ \\
\hline Gamma-Glutamyl Transferase (GGT) & $39.57 \pm 39.91$ \\
Alkaline Phosphatase (ALP) & $51.20 \pm 23.03$ \\
Albumin & $540.64 \pm 712.29$ \\
\hline
\end{tabular}

TABLE 5: Liver biochemistries 


\section{Cureus}

\begin{tabular}{|l|l|}
\hline \multicolumn{1}{|l|}{ (N=31) } \\
\hline Time since diagnosis of HCV (median) & 9 months \\
\hline GeV genotype & \\
\hline Genotype 3 & $10(32.30 \%)$ \\
\hline Treatment status & $21(67.70 \%)$ \\
\hline Treatment naïve & \\
\hline Treatment experienced & $25(80.6 \%)$ \\
\hline PEG-interferon & $6(19.4 \%)$ \\
Conventional interferon & $3(50.0 \%)$ \\
\hline
\end{tabular}

\section{TABLE 6: Viral/HCV/serological and treatment status}

HCV: Hepatitis C Virus; PEG-Interferon: Pegylated Interferon

\section{Primary outcome with subgroup analysis}

A good number (87.09\%) of patients achieved a sustained vIrological response (SVR). The response was equally distributed through genotype, etiology, and treatment naïve vs. experienced groups. There were only four relapses in the entire study, and they were found to be statistically insignificant overall. The primary outcome and subgroup analysis are shown in Table 7 and Table 8 , respectively.

\begin{tabular}{|l|l|l|l|}
\hline $\mathbf{( N = 3 1 )}$ & Rapid virological response (04 weeks) & Early virological response (12 weeks) & Sustained virological response (52 weeks) \\
\hline Achieved & $29(93.5 \%)$ & $29(93.5 \%)$ & $27(87.09 \%)$ \\
\hline Not achieved & $2(6.5 \%)$ & $2(6.5 \%)$ & $4(12.9 \%)$
\end{tabular}

\section{TABLE 7: Primary outcome}




\section{Cureus}

\begin{tabular}{|c|c|c|c|}
\hline Cause of CKD & SVR & Genotype 1 & Genotype 3 \\
\hline \multirow{2}{*}{ Hypertension } & Achieved & 2 & 10 \\
\hline & Not achieved & Nil & Nil \\
\hline \multirow{2}{*}{ Miscellaneous } & Achieved & 3 & 3 \\
\hline & Not achieved & Nil & 1 \\
\hline \multirow{2}{*}{ BSSKD } & Achieved & Nil & 4 \\
\hline & Not achieved & 2 & Nil \\
\hline \multirow{2}{*}{ Diabetes } & Achieved & 2 & 1 \\
\hline & Not achieved & 1 & Nil \\
\hline \multirow{2}{*}{ Stones } & Achieved & Nil & 2 \\
\hline & Not achieved & Nil & 0 \\
\hline \multirow{2}{*}{ Treatment naive } & Achieved & 7 & 15 \\
\hline & Not achieved & 2 & 1 \\
\hline \multirow{2}{*}{ Treatment experienced } & Achieved & Nil & 5 \\
\hline & Not achieved & 1 & Nil \\
\hline \multirow{2}{*}{ Overall } & Achieved & $7(70.0 \%)$ & $10(90.90 \%)$ \\
\hline & Not achieved & $3(30.0 \%)$ & $1(9.10 \%)$ \\
\hline
\end{tabular}

\section{TABLE 8: Subgroup analysis}

CKD: Chronic Kidney Disease, BSSKD: Bilateral Small Size Kidney Disease

\section{Secondary outcome}

There was no development of overt cirrhosis or decompensation of liver function at all. Twenty-seven patients continued on maintenance hemodialysis after achieving SVR. Two patients had a relapse of HCV although no deterioration in renal function was seen until the completion of the study. Two patients succumbed to ESRD and its natural disease progression. Overall survival was $93.54 \%$ at one year. Table 9 summarizes the secondary outcomes. 


\section{Cureus}

\begin{tabular}{|c|c|c|c|}
\hline Cause of CKD & SVR & Genotype 1 & Genotype 3 \\
\hline \multirow{2}{*}{ Hypertension } & Achieved & 2 & 10 \\
\hline & Not achieved & Nil & Nil \\
\hline \multirow{2}{*}{ Miscellaneous } & Achieved & 3 & 3 \\
\hline & Not achieved & Nil & 1 \\
\hline \multirow{2}{*}{ BSSKD } & Achieved & Nil & 4 \\
\hline & Not achieved & 2 & Nil \\
\hline \multirow{2}{*}{ Diabetes } & Achieved & 2 & 1 \\
\hline & Not achieved & 1 & Nil \\
\hline \multirow{2}{*}{ Stones } & Achieved & Nil & 2 \\
\hline & Not achieved & Nil & 0 \\
\hline \multirow{2}{*}{ Treatment naive } & Achieved & 7 & 15 \\
\hline & Not achieved & 2 & 1 \\
\hline \multirow{2}{*}{ Treatment experienced } & Achieved & Nil & 5 \\
\hline & Not achieved & 1 & Nil \\
\hline \multirow{2}{*}{ Overall } & Achieved & 7 (70.0\%) & $10(90.90 \%)$ \\
\hline & Not achieved & $3(30.0 \%)$ & $1(9.10 \%)$ \\
\hline
\end{tabular}

TABLE 9: Secondary outcomes

CKD: Chronic Kidney Disease, BSSKD: Bilateral Small Size Kidney Disease

\section{Discussion}

There is little data available on HCV infected patients with CKD on maintenance hemodialysis in Pakistan. Most studies that are present tend to look at the prevalence, risk factors, genotypes, and treatment outcomes with PEG-interferon rather than DAAs. No data was available on treatment with DAAs in this group even five years after first approval of SOF. Thus, we were breaking new ground when we started this study.

The prevalence of active HCV infection for patients on maintenance hemodialysis was found to be $38.75 \%$. This is much higher than what was stated by Khokar N et al. [9]; the prevalence of HCV was reported to be 23.7\%. However, Gul A et al. [10] reported the prevalence to be $68 \%$ in similar patients. Other studies have estimated the prevalence to be as high as $73 \%$.

The limited data that is available in Pakistan points to a high prevalence of HCV in patients going under hemodialysis. Therefore, vigorous screening protocols should be instituted as early detection before the development of cirrhosis and treatment with DAAs confer greatly reduced morbidity and mortality as we discuss below.

Most patients were female and married (housewives). No correlation between CKD and HCV acquisition to the occupation of the patients could be made. The relatively "young" median age of our patients can be attributed to early causes of CKD such as pregnancy-induced renal disease, bilateral small size kidney disease (BSSKD), and echogenic kidneys.

CKD is associated with iron deficiency anemia and low mean corpuscular volume (MCV). But our patients were already taking preventive measures against this, thus $\mathrm{Hb}$ and MCV were fairly well-controlled. No immunocompromised patients were inducted into the study and neither were any cirrhotics, as such white blood cells and platelets were within normal ranges.

With a median time since the start of dialysis of three years, almost all patients were undergoing the thriceweekly dialysis routine. Since we could not identify clear-cut risk factors for the transmission of HCV with the exception of hemodialysis itself, it is the opinion of the authors that most patients were infected after 
the initiation of maintenance hemodialysis. This also corresponds to the time of diagnosis of HCV, i.e. nine months median.

Hypertension and diabetes constituted more than half of all the causes of CKD in this study. These are associated with a high risk of CKD developing ESRD requiring hemodialysis [11]. BSSKD, yet another disease that affects primarily a younger age group, was also prevalent. Singular cases of amyloidosis and chronic tubulointerstitial nephritis were also seen.

The most common subtype for HCV is genotype 3 in Pakistan and this was reflected in our study, with $67.70 \%$ patients exhibiting the said genotype. Only six patients had previously taken medications for HCV, to no avail (see Table 6). Both PEG-interferon and conventional interferon were prescribed for one year in all six patients. These treatments were carried out before the licensed used of DAAs in Pakistan.

Since all patients were CHC and noncirrhotic, the liver function tests (LFTs) are representative of this. The raised alkaline phosphatase (AP) could not be attributed to $\mathrm{CHC}$ but to $\mathrm{CKD}$. For the most part, patients with $\mathrm{CKD}$ have $\mathrm{AP}$ in the nonpathological ranges with higher than normal means [12]. In our study, this equation was disrupted by the two cases of multiple myeloma, which raised the mean significantly.

The overall SVR achieved at one year in our study was $87.09 \%$. Previously, SVRs ranging from 58\% to $100 \%$ have been reported using the SOF-based regimen in patients undergoing hemodialysis [13]. These studies did not use DAC as the second drug. The treatment outcome for HCV GT-3 was better than GT-1; the SVR achieved for GT-1 was similar to that reported for the region [14-15], whereby worsening CKD is associated with lower SVRs and viral elimination.

Good results have been seen with DAAs for both treatment experience and naïve patients. This was the case in our study, with both groups showing similar SVR rates. The difference was statistically nonsignificant. The highest number of relapses was seen in the BSSKD group. One-third of the patients with BSSKD relapsed at one year; all were GT-1, which is also the most probable cause of this phenomenon.

Survival at one year was 93.54\%. Despite having active HCV and CKD for a considerable time, our patients did not show any deterioration in liver function. This is not to say that both diseases do not affect each other in a bidirectional manner. This simply indicates that if treated earlier, HCV elimination reduces mortality considerably. Patients that were found to be cirrhotics or decompensated were not inducted into the study; this too contributed to the high SVR achieved and survival rates.

Of the two patients that passed away, both had relapsed at one year. Still, there was no deterioration of the liver function to the decompensated state. The cause of death in both cases was the natural progression of ESRD. Two other patients relapsed as well and continued their CKD treatment while awaiting approval for newer DAAs.

Throughout the study, no major side effects were noted with the use of DAAs. No patients were lost to follow-up nor did they fall back on their nephrological consults and dialysis sessions. Few shortcomings were associated with this study. The sample size was too small, but this did constitute a major bulk of CKD patients requiring hemodialysis in our center. Patients were only followed up for one year with respect to their virological response. Whether HCV relapse occurred after that or not was not analyzed.

Furthermore, the effect and interactions of drugs already being taken by the patients with the DAAs were not evaluated either. IL28 B genotyping was not done. While it was made sure that patients were taking adequate calories, a complete nutritional assessment was not carried out throughout the study.

\section{Conclusions}

We conclude that the burden of HCV in patients on hemodialysis is high. Treatment before the development of cirrhosis reduces mortality. SOF plus DAC is well-tolerated and effective in the treatment of CHC in these patients; it is also associated with an improved survival rate. Until newer DAAs are made available in Pakistan, we recommend this regimen.

\section{Additional Information \\ Disclosures}

Human subjects: Consent was obtained by all participants in this study. Professor AR Jamali, Chairman Institutional Review Board Committee, JPMC issued approval NO. F.2- 81/2019-GENL/10001/JPMC. Animal subjects: All authors have confirmed that this study did not involve animal subjects or tissue. Conflicts of interest: In compliance with the ICMJE uniform disclosure form, all authors declare the following: Payment/services info: All authors have declared that no financial support was received from any organization for the submitted work. Financial relationships: All authors have declared that they have no financial relationships at present or within the previous three years with any organizations that might have an interest in the submitted work. Other relationships: All authors have declared that there are no other 


\section{References}

1. Hasan M, Sutradhar I, Gupta RD, Sarker M: Prevalence of chronic kidney disease in South Asia: a systematic review. BMC Nephrol. 2018, 23:291. 10.1186/s12882-018-1072-5

2. Murtagh FE, Marsh JE, Donohoe P, Ekbal NJ, Sheerin NS, Harris FE: Dialysis or not? A comparative survival study of patients over 75 years with chronic kidney disease stage 5. Nephrol Dial Transplant. 2007, 22:19551962. 10.1093/ndt/gfm153

3. Kuragano T, Matsumura O, Matsuda A, et al.: Association between hemoglobin variability, serum ferritin levels, and adverse events/mortality in maintenance hemodialysis patients. Kidney Int. 2014, 86:845-854. 10.1038/ki.2014.114

4. Zhang H, Li L, Jia H, et al.: Surveillance of dialysis events: one-year experience at 33 outpatient hemodialysis centers in China. Sci Rep. 2017, 21:249. 10.1038/s41598-017-00302-9

5. Lee MH, Yang HI, Lu SN, et al.: Chronic hepatitis C virus infection increases mortality from hepatic and extrahepatic diseases: a community-based long-term prospective study. J Infect Dis. 2012, 15:469-477. 10.1093/infdis/jis385

6. Fabrizi F, Dixit V, Messa P: Impact of hepatitis C on survival in dialysis patients: a link with cardiovascular mortality?. J Viral Hepat. 2012, 19:601-607. 10.1111/j.1365-2893.2012.01633.x

7. Prabhu RA, Nair S, Pai G, Reddy NP, Suvarna D: Interventions for dialysis patients with hepatitis C virus (HCV) infection [Article in English, Spanish]. Cochrane Database Syst Rev. 2015, 2015:CD007003. 10.1002/14651858.CD007003.pub2

8. Roth D, Nelson DR, Bruchfeld A, et al.: Grazoprevir plus elbasvir in treatment-naive and treatmentexperienced patients with hepatitis $C$ virus genotype 1 infection and stage 4-5 chronic kidney disease (the C-SURFER study): a combination phase 3 study. Lancet. 2015, 17:1537-1545. 10.1016/S01406736(15)00349-9

9. Khokhar N, Alam AY, Naz F, Mahmud SN: Risk factors for hepatitis C virus infection in patients on longterm hemodialysis. J Coll Physicians Surg Pak. 2005, 15:326-328.

10. Gul A, Iqbal F: Prevalence of hepatitis C in patients on maintenance haemodialysis . J Coll Physicians Surg Pak. 2003, 13:15-18.

11. Jessani S, Bux R, Jafar TH: Prevalence, determinants, and management of chronic kidney disease in Karachi, Pakistan - a community based cross-sectional study. BMC Nephrol. 2014, 13:90. 10.1186/1471-2369-15-90

12. Okoye JU, Arodiwe EB, Ulasi II, Ijoma CK, Onodugo OD: Prevalence of CKD-MBD in pre-dialysis patients using biochemical markers in Enugu, South-East Nigeria. Afr Health Sci. 2015, 15:941-948. 10.4314/ahs.v15i3.31

13. Fabrizi F, Lampertico P, Messa P: Direct-acting antiviral agents, hepatitis $C$ and dialysis: an update [Article in Italian]. G Ital Nefrol. 2018, 35: pii: 2018-vol5.

14. Fabrizi F, Donato FM, Messa P: Direct-acting antivirals for hepatitis $C$ virus in patients on maintenance dialysis. Int J Artif Organs. 2017, 13:531-541. 10.5301/ijao.5000613

15. Shin HP, Park JA, Burman B, Kozarek RA, Siddique A: Efficacy and safety of sofosbuvir-based regimens for treatment in chronic hepatitis $\mathrm{C}$ genotype 1 patients with moderately impaired renal function. Clin Mol Hepatol. 2017, 23:316-322. 10.3350/cmh.2016.0087 